\title{
Consensus recommendations for the use of vacuum-assisted breast biopsy under sonographic guidance
}

\author{
U. Krainick-Strobel • M. Hahn • V. F. Duda • S. Paepke • \\ U. Peisker • S. Petrich • P. Scheler • U. Schwarz-Böger • \\ H. P. Sinn • S. Heywang-Köbrunner • I. Schreer
}

Received: 28 May 2006 / Accepted: 2 August 2006 / Published online: 12 October 2006

(C) Springer-Verlag 2006

\begin{abstract}
In combination with high-resolution ultrasound (US), vacuum-assisted biopsy (VB) is a patient friendly, outpatient diagnostic procedure with the potential for curative resection of selected lesions and thus represents a valuable supplement to microbiopsy procedures already established. The indication spectrum for US-guided VB is still under discussion. The Minimally Invasive Breast Procedures Study Group (AG MiMi) of the German Senology Society gives recommendations for indications, the investigators' qualifications, technical requirements,
\end{abstract}

E-mail address for Minimally Invasive Breast Procedures Study Group (AG MiMi): agmimi@joho.de.

Minimally Invasive Breast Procedures Study Group (Arbeitsgemeinschaft Minimalinvasive Mammainterventionen; AG MiMi) of the German Senology Society (Deutsche Gesellschaft für Senologie).

U. Krainick-Strobel $(\bowtie) \cdot$ M. Hahn

Department of OB/GYN, Breast Centre,

University Hospital Tuebingen,

Calwerstr. 7,

Tuebingen 72076, Germany

e-mail: ute.krainick@uni-tuebingen.de

V. F. Duda

Breast Centre, University Hospital Marburg,

Baldinger Str.,

35033 Marburg, Germany

S. Paepke $\cdot$ U. Schwarz-Böger

Department of OB/GYN, Breast Centre,

University Hospital Munich Technische Universitaet,

Ismaninger Str. 22,

81675 Munich, Germany

U. Peisker

Department of OB/GYN, Breast Centre, Erkelenz Hospital,

Tenholter Str. 43,

41812 Erkelenz, Germany documentation, quality assurance and follow up intervals necessary for the procedure. These consensus recommendations consolidate the recommendations for experts in this field and have not been formulated as guidelines. Results from further studies must support and, where necessary, supplement the recommendations made so far.

Keywords Ultrasound-assisted vacuum breast biopsy . Benign breast lesions $\cdot$ Hand-held Mammotome ${ }^{\circledR}$.

Minimally invasive breast interventions

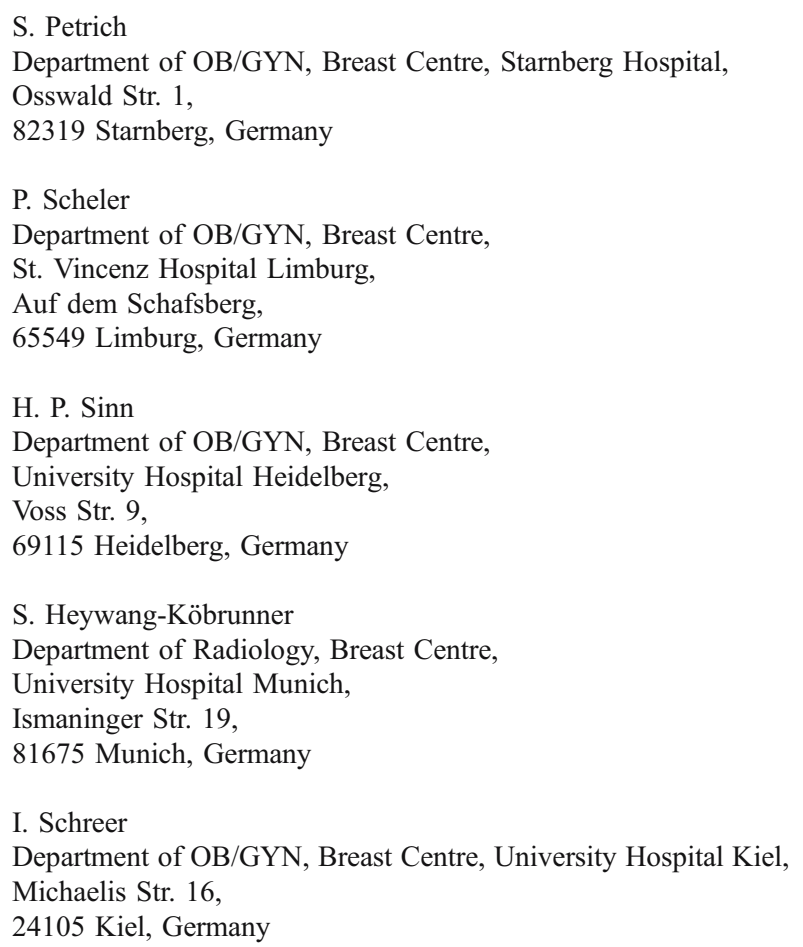




\section{Introduction}

Established diagnostic techniques in breast diagnostics using accelerated core needle biopsy (ACNB) are complemented today by large needle gauge VB techniques. Whilst stereotactically guided VB is a well-established procedure [1, 2], the scope of use for US-guided VB is still a matter of debate $[3,4,14]$. VB under radiological guidance has been available in Germany since 1998. The introduction of the hand-held ( $\mathrm{HH})$ Mammotome $^{\circledR}$ (Ethicon Breastcare) in early 2000 made US-guided VB for the diagnosis of breast lesions possible. A further system, the Bard Vacora ${ }^{\circledR}$ VB-system, has been available since 2002. VB has already been incorporated into the S3-guideline "Brustkrebs-Früherkennung in Deutschland" (Early Recognition of Breast Cancer in Germany) [5]. The clinical findings made by the users in the AG MiMi that form the basis for these recommendations were obtained using the HH Mammotome ${ }^{\circledR}$.

Eighty percent of all breast lesions can be visualised sonographically and should be clarified under US-guidance. The majority of these lesions (approx. 80\%) can be histologically clarified with excellent sensitivity and specificity with ACNB [6-8]. Many of the lesions can easily be removed using $\mathrm{VB}$ and this technique has therefore broadened the minimally invasive biopsy method spectrum, since the method is also suitable for diagnostic biopsy with curative intent, i.e., removal of lesions found at diagnostic imaging.

The costs of the procedure are not currently reimbursed by statutory health insurance organisations. One of the aims of these Consensus Recommendations is to change this so that all patients for whom VB is indicated will be able to benefit from the procedure.

These Consensus Recommendations consolidate the recommendations for experts in this field and have not been formulated as guidelines. Only statements where consensus has been achieved are included. Other methods and modifications of the procedures described are being used (such as VB under 3D/4D visualization; VB with high frequency probes [9]). Consensus has, however, yet to be reached on these.

\section{Consensus findings}

The consensus statements were the result of preliminary meetings of coordinators, spokespersons and members of the AG MiMi in 2004 (Esslingen 17 April; Norderstedt 12 May; Frankfurt 4 July; Bayreuth 30 July). They were presented at the annual congress of the German Senology Society on 4 September 2004 in Freiburg. After further refinement, the final text was presented to all members of
AG MiMi on 3 December 2004 in Frankfurt and in February 2005 to the executive board of the DGS for final amendments. Important individual points of criticism where consensus was not reached are specified in the discussion. The items listed under "Results" were adopted unanimously.

These Consensus Recommendations are modelled on the style of the interdisciplinary consensus regarding the use and techniques of stereotactic VB [1]. The Austrian Breast Imaging Study Group [10] has also published consensus recommendations on the use of stereotactically- and USguided VB.

\section{Results}

Imaging

\section{Mammography (MG)}

Before investigation, the patient's medical history must be documented, she must have undergone a clinical examination, and complete imaging must be available.

A two-plane MG no more than six months old must be available for patients $\geq 40$ years before VB. For some women under 40 years, a one- or two-plane unilateral or bilateral MG is indicated.

\section{Ultrasound/Investigator qualifications}

The investigator's qualifications should comply with DEGUM level II (Deutsche Gesellschaft für Ultraschall in der Medizin - German Society for Clinical Ultrasonography) [11].

The DEGUM stipulates that the investigator is required to perform 30 microbiopsies under the supervision of an experienced colleague, whereby the first procedures should be ACNBs. Additionally, the investigator must perform and document 50 ACNBs alone. It is recommended that participants of a VB course should perform the first 10 VBs under the supervision of an experienced colleague. The regular performance of a minimum of 50 percutaneous biopsies under sonographic guidance per year is required (S3-guideline, page 96; http://www.DEGUM.de).

Before performing the $\mathrm{VB}$, the lesion of interest must be imaged in two planes and its three-dimensional measurements and site must be documented. The findings must include a BI-RADS (Breast Imaging Reporting and Data System)-compliant B I-V malignancy estimate (B III $\leq 2 \%$ probability of malignancy, B IV 3-94\% probability of malignancy, $B \quad V \geq 95 \%$ probability of malignancy) [12]. 
Technical requirements

US device

The US device must be able to image the breast from the skin to the pectoral fascia, including the lesion. The needle pathway must be visible up to the edge of the image, and the tip of the needle and the sample window in the needle must be fully visualisable.

\section{Selection of needle size}

The choice of needle size should be governed by the nature of the application and the size of the lesion. If the goal is to remove the lesion, an eight-gauge rather than an 11 gauge needle should be chosen for lesions that are $10 \mathrm{~mm}$ or larger.

Informing the patient

In cases of strictly diagnostic investigations

As for ACNB, the following possible complications should be described and discussed:

- Infection, disturbed would healing

- Bleeding, haematoma

- Trauma to skin, breast wall, pleura, lungs and heart

- False-negative diagnosis

- Need for follow-up surgery

- Affect on cosmetic appearance

- Allergic reactions to local anaesthesia

The patients must also be given information on the following:

- Follow-up and subsequent contact, as well as documentation of monitoring from outside clinicians e.g., commissioned monitoring

- Preoperative and postoperative patient instructions (dos and don'ts)

\section{Informing the patient in cases of extirpative $V B$}

In addition to the items, in cases of strictly diagnostic investigations, the patient should be told the following:

Residues which cannot be visualized sonographically might remain in the breast. Further investigations may possibly not differentiate between newly formed scar tissue, residual tissue from the lesion, and new tumour growth.

It must be explained that the procedure is under evaluation. Pure image monitoring (for BI-RADS III lesions) and open surgical biopsy must be named as alternatives.
Indications

The choice of ACNB or VB depends on the nature of the lesion of interest and the degree of surgical precision required. The most important aim is the reliable extraction of all of the target tissue (S3-guideline, p. 109-110).

The criteria for a VB are as follows:

1. Suspected carcinoma following ACNB (BI-RADS IV/ $\mathrm{V}$, mismatch of the results from imaging and histology).

2. Suspected lesion (BI-RADS IV/V) about $5 \mathrm{~mm}$ in diameter.

Criteria for diagnostic resection:

3. Presence of intraductal or intracystic growths (e.g. single papillomas).

4. Resection of a clearly benign but symptomatic lesions (e.g., fibroadenoma or cysts).

Interdisciplinary meeting is required, especially for indications 3 and 4, and the appropriateness of this approach as an alternative to open excision biopsy should be considered. These interventions should be performed only at centres with a verifiable biopsy rate in line with EU directives. Also after interdisciplinary meeting, specialized centres where all imaging methods and interventional techniques are routinely performed can also use this method for other indications in individual cases (see Discussion).

Surgical procedure

Number of tissue specimens

With an 11 gauge VB needle, a minimum of 10 specimens should be removed; with an eight-gauge needle, at least six specimens should be removed.

\section{Local anaesthesia}

The procedure is to be performed under adequate local anaesthesia, taking into consideration surgical and cosmetic aspects (S3-guideline, p. 110). In the case of lesions that are difficult to delineate, the excessive use of local anaesthesia or the haematoma induced by VB can complicate sonographic imaging or lead to the procedure being stopped.

\section{Dressing}

Following the procedure, a compression dressing and manual compression should be applied if haemostasis is necessary. Alternatively, Steri-Strips can be applied over the incision. 


\section{Documentation}

Documentation is carried out in accordance with the documentation requirements in the S3-Leitlinie ("S3 guidelines") on early breast cancer detection (p. 112):

\section{Image documentation}

Before VB, imaging must be performed in two planes and lesion metrics (length, width and depth) and site (side, clock position, and distance from nipple to lesion) are to be documented on the image. During VB, further imaging documentation in two planes must be performed, and after the blood has been aspirated from the biopsy cavity.

\section{Written documentation}

Site (side, clock position, distance from nipple to lesion), metrics in two planes (three diameters are to be measured: height, depth and width), and the distance between the skin and lesion must be documented. Furthermore, whether or not extirpation was attempted, the number of specimens removed and the needle size used must be specified. In the diagnostic findings, the US device type used and the frequency of the US head should be given. Technical and medical complications are to be recorded, and the needle pathway (e.g., lateral to medial) must always be described.

The following must be documented:

Whether excision of the lesion was:

\section{- Complete}

- Representative

- Non-representative

- Unclearly representative

- Definitely non-representative

The histological findings and images are compared to establish whether they match. This final assessment must include recommendations on further measures and followup intervals.

Pathology quality assurance

Tissue specimens are fixed in neutral buffered formalin, and the number of specimens sent to the laboratory is to be documented.

Frozen sections of VB biopsy specimens are to be avoided.

For pathological investigation, specimens removed with 11 gauge and eight-gauge needles are usually processed in 6-8 section levels. The number of section levels may vary according to the suspected diagnosis indicated by the imaging, lesion size and the number of specimens that are to be investigated.
The pathomorphological findings should be divided into five categories (B1-5) and documented with the final assessment in the findings [13].

Follow-up intervals

According to the S3-guidelines [5], clinical and sonographic follow-up should be performed 6 and 24 months following the procedure, if possible by the original investigator. If this is not possible, the centre that performed the VB should request the follow-up findings for their own quality control purposes. Sonographic assessment of the biopsy cavity, any residues, scarring or recurrent lesions is performed.

Quality assurance

Any mismatch between the imaging and histological findings is a matter for interdisciplinary meeting. Recommendations as to how to proceed are then given.

The AG MiMi is currently developing an Internet-based voluntary central biopsy registry. All concerned are encouraged to contribute. Until its establishment, documentation will be carried out on specific microbiopsy documentation forms, which can be downloaded at present in German from the $\mathrm{AG}$ MiMi website at http://www. senologie.org. $\rightarrow$ AG MiMi.

\section{Discussion}

These Consensus Recommendations are based on results published to date on the use of VB under sonographic guidance for the diagnosis and treatment of breast lesions and the experience of the users who took part in the consensus discussions. As the knowledge base on VB increases, these recommendations will be amended.

\section{Indications}

Four indications for the use of US-guided VB were identified during the consensus meetings as mentioned above.

No consensus was reached on the following possible further areas of use for US-guided VB: a) diagnostic resection of, above all, fibrotic scarring and liponecrosis, and $b$ ) exclusion of a recurrence of BI-RADS IV disease after breast-conserving surgery. Us-guided VB has been used in these two indications, primarily for patients who are alarmed about unclear palpation or US findings in scarred regions and would otherwise undergo surgery for 
clarification or removal of the lesion. The high sensitivity of magnetic resonance imaging can be exploited in such situations and this is preferable to an invasive clarification. c) Some surgeons use VB to investigate unclear palpation findings and so-called "mastopathic areas" (BI-RADS III, IV), often in younger patients with risk factor histories whose breasts are difficult to assess. The reason for this is the possibility of obtaining a larger sample volume from a wider area of tissue, thus enhancing the diagnostic reliability (exclusion of lobular breast cancer, ductal carcinoma in situ, atypical ductal hyperplasia [DIN 1b]). Current publications have not demonstrated that this procedure is superior to fan-shaped microbiopsy with ACNB using a $14 \mathrm{G}$ needle. d) A further possible indication for US-guided VB is for sonographically detectable, suspected microcalcifications when there is a clear correlation with MG findings (specimen $\mathrm{x}$-ray). This would spare the patient the more extensive procedure under stereotactic MG control. e) Other extremely rare indications for US-guided VB may be the reduction or resection of a symptomatic galactocele or a symptomatic haematoma (e.g., before radiotherapy following breast conserving therapy).

In the view of the consensus committee, these (a-e) are not yet generally valid indications and require further evaluation. These indications were not agreed upon by the consensus group, always require interdisciplinary meetings, and should be reserved for specialist centres.

\section{The therapeutic potential of VB in cases of benign symptomatic lesions}

In vitro studies with gel models on turkey phantoms to imitate benign lesions have been shown that lesions with a diameter of up to $10 \mathrm{~mm}$ can be extirpated with an $11 \mathrm{G} \mathrm{VB}$ needle, and that lesions measuring up to $18 \mathrm{~mm}$ in diameter can be removed with an $8 \mathrm{G}$ needle [4]. These experimental data are supported by existing literature on US-guided complete extirpations. Sperber et al. [15] achieved a complete sonographic resection rate of $100 \%$ for lesions up to $15 \mathrm{~mm}$ in diameter, but only a $55 \%$ resection rate for $>15 \mathrm{~mm}$ lesions ( $\mathrm{n}=56$, follow-up: 2 years). Hahn et al. [16] achieved a complete resection rate of $87 \%$ for lesions of $<20 \mathrm{~mm}$, and $68 \%$ for $>20 \mathrm{~mm}$ lesions after a mean follow-up of three months. Johnson et al. [17], Fine et al. $[18,19]$, and March et al. [20] have all reported comparable results. Successful extirpation is very difficult to assess under imaging immediately after VB due to the haematoma, and the conclusive assessment of the successful extirpation of a lesion can only be carried out 3 to 6 months after the procedure.

\section{Limitations of the method}

VB requires considerable expertise, particularly when conducted with curative intent, and should therefore only be performed at centres that have experience in interventional breast diagnostics. Extremely mastopathic breasts or lesions lying very close to the breast wall or skin can complicate or prolong the procedure. Little experience with complications has so far been made, but they appear to be similar to those of ACNB. Occasionally, heavy bleeding occurs during the procedure, which does not require further surgical measures, but does complicate sonographic assessment and follow-up investigations.

Although the consensus of Hewang-Koebrunner et al. [1] makes a recommendation regarding the number of tissue specimens that should be removed during radiological VB, there are few published results on the number of specimens that should be removed during sonographically guided VB. Studies conducted by the working group on in vitro models suggest that after complete extirpation performed under imaging, an additional 4-5 specimens should be removed in a clockwise direction (KrainickStrobel, personal communication).

The material costs and time expenditure for outpatient VBs must be compared with those of an open biopsy and not with those of an ACNB.

\section{Outlook}

US-guided VB is a patient friendly, outpatient diagnostic procedure with the potential for curative resection of selected lesion and thus represents a valuable supplement to microbiopsy procedures already established. Results from further studies must support and, where necessary, supplement the recommendations made so far.

Acknowledgements The authors would like to thank the following persons for providing helpful comments and advice on these recommendations:

Dr. F. Degenhardt (Bielefeld), Dr. H. Madjar (Wiesbaden), Dr. M. Müller-Schimpfle (Frankfurt M.), Dr. J. Hoffmann (Frankfurt Hoechst), Dr. R. Schulz-Wendtland (Erlangen), Dr. K. Siegmann (Tübingen), Dr. G. Raute (Oberstaufen).

\section{References}

1. Heywang-Köbrunner SH, Schreer I, Decker Th, Böcker W (2003) Interdisciplinary consensus on the use and technique of vacuum assisted stereotactic breast biopsy. EJR 47(3):232-236

2. Kettritz U, Rotter K, Schreer I, Murauer M, Schulz-Wendtland R, Peter D, Heywang-Köbrunner S (2004) Stereotactic vacuumassisted breast biopsy in 2874 patients. Cancer 100:245-251 
3. Scheler P, Pollow B, Hahn M, Kuner RP, Fischer A, Hoffmann G. Die handgeführte Vakuumsaugbiopsie von Mammaläsionen unter sonographischer Kontrolle-erste Erfahrungen. Zentralbl Gynakol 122:472-75

4. Krainick (2002) AKF (angewandte klinische Forschung - applied clinical research) research project of the University of Tübingen, Poster 10/2002 at the final colloquium

5. Schulz et al (2003) S-3 Leitlinie zur Brustkrebsfrüherkennung. In: Schulz KD, Albert US (eds) Zuckschwerdt Verlag, ISBN 388603-812-2

6. Liberman L (2000) Centennial dissertation. Percutaneous imaging-guided core breast biopsy: state of the art at the millennium. AJR 174(5):1191-1199

7. Parker SH, Burbank F, Jackman RJ (1994) Percutaneous large core breast biopsy: a multi-institutional study. Radiology 193:359

8. Schulz-Wendtland R, Kramer S, Lang N, Bautz W (1998) Ultrasonographic guided microbiopsy in mammary diagnosis: indications, technique and results. Cancer Res 18:2145-2146

9. Baez E, Huber A, Vetter M, Hackeloer BJ (2003) Minimal invasive complete excision of benign breast tumors using a threedimensional ultrasound-guided mammotome vacuum device. Ultrasound Obstet Gynecol 21:267-272

10. Helbich TH, Buchberger W, Rudas M; Austrian Breast Imaging Study Group (ABISG) (2002) Konsensuspapier: stereotaktisch und Ultraschall gezielte Vakuumbiopsie von Brustläsionen. Rofo 174(4):517-522

11. http://www.degum.de: Mehrstufenkonzept des Arbeitskreises Mammasonographie der DEGUM

12. American College of Radiology (ACR) (2003) Breast Imaging Reporting and Data System (BI-RADS ${ }^{\mathrm{TM}}$ ) 4th edn. Reston, (VA) American College of Radiology
13. Perry N, Broeders M, de Wolff C, Törnberg S (2001) European guidelines for quality assurance in mammography screening, 3rd edn. European Commission, Luxemburg

14. Krainick U, Meyberg-Solomayer G, Majer I, Berning S, Hess S, Krauss K, Schiebeler A, Smyczek-Gargya B, Janzen J, MüllerSchimpfle M, Wallwiener D, Fersis N (2002) Minimal invasive mammabiopsien: Die Vakuumbiopsie (VB) mit dem Handheld (HH) mammotome ${ }^{\mathrm{TM}}$ unter Ultraschallsicht - Erfahrungen und Indikationsspektrum des Brustzentrums Tübingen. Geburtsh Frauenheilk 62:346-350

15. Sperber F, Blank A, Metser U, Flusser G, Klausner JM, LevChelouche D (2003) Diagnosis and treatment of breast fibroadenomas by ultrasound-guided vacuum-assisted biopsy. Arch Surg 138:796-800

16. Hahn M, Krainick U, Peisker U, Krapfl E, Paepke S, Scheler P, Duda V, Petrich S, Knauert K, Hoffmann J (2004) Eignet sich das handheld mammotome zur kompletten entfernung benigner Läsionen der Brust? Geburtsh Frauenheilk 64:719-722

17. Johnson AT, Henry-Tillman RS, Smith LF, Harshfield D, Korourian S, Brown H, Lane S, Colvert M, Klimberg VS (2002) Percutaneous excisional biopsy. Am J Surg 184:550-554

18. Fine RE, Beth A, Boyd BA, Pat W, Whitworth PW, Kim JA, Harness JK, Burak WE (2002) Percutaneous removal of benign breast masses using a vacuum-assisted hand-held device with ultrasound guidance. Am J Surg 84:332-336

19. Fine RE, Whitworth PW, Kim JA, Harness JK, Boyd BA, Burak WE (2003) Low-risk palpable breast masses removed using a vacuum-assisted hand-held device. Am J Surg 186(4):362-367

20. March DE, Coughlin BF, Barham RB, Goulart RA, Klein SV, Bur ME, Frank JH, Makari-Judson G (2003) Breast masses: removal of all US evidence during biopsy by using a handheld vacuumassisted device-initial experience. Radiology 27:549-555 